\title{
Treatment of hyperkalaemia using intravenous and nebulised salbutamol
}

\author{
R J McClure, V K Prasad, J T Brocklebank
}

\begin{abstract}
In 11 children (aged 5-18 years) with end stage chronic renal failure, the effect on plasma potassium of two doses of salbutamol (separated by two hours) given intravenously $(4 \mu \mathrm{g} / \mathrm{kg})$ and on a separate date, of salbutamol administered by nebuliser $(2.5 \mathrm{mg}$ if the child weighed below $25 \mathrm{~kg}, 5 \mathrm{mg}$ if above) was observed. Within 30 minutes of the first dose, the mean plasma potassium concentration fell significantly by 0.87 and $0.61 \mathrm{mmol} / 1$ after intravenous and nebulised administration respectively. Sixty minutes after the second dose the plasma potassium was significantly reduced by a further 0.28 and 0.53 $\mathrm{mmol} / 1$ respectively. There was a significant difference between the two methods of administration at 300 minutes after the first dose favouring nebulisation. No major side effects were observed. Nebulised salbutamol should be the first choice emergency treatment of hyperkalaemia.

(Arch Dis Child 1994; 70: 126-128)
\end{abstract}

Hyperkalaemia is a frequent complication in children with renal failure, and may be recurrent in those in the end stage chronic state. It is a medical emergency because of its potentially lethal complication of cardiac arrhythmias, particularly asystole.

An ideal emergency treatment should be effective, reliable, predictable, fast in its onset of action and, most importantly, safe. It would appear that no treatment presently used fulfils these criteria well with the possible exception of salbutamol. Although salbutamol is being increasingly used it has undergone relatively little assessment particularly in children.

We therefore have determined to compare the relative efficacies of salbutamol, administrated by the intravenous and nebulised route, to reduce plasma potassium concentrations in patients with end stage chronic renal failure.

Academic Unit of Paediatrics and Child Health, St James's University Hospital, Beckett Street, Leeds LS9 7TF

R J McClure

V K Prasad

J T Brocklebank

Correspondence to: Dr McClure.

Accepted 8 October 1993
Patients and methods

Two treatment regimens were designed, one involved giving salbutamol by intravenous administration, the second by the nebulised route. Over a period of six months 11 children were recruited. All received both treatment regimens except for two patients. One could not tolerate a mask on her face because of claustrophobia and therefore did not receive the nebulised treatment. The other received a renal transplant before undergoing the intravenous treatment.
Children were recruited who had end stage chronic renal failure and had received maintenance dialysis at the Yorkshire Paediatric Nephrology Unit, St James's Hospital, Leeds for at least three months before inclusion. They were also required to have had a plasma potassium concentration higher than 5.5 $\mathrm{mmol} / \mathrm{l}$ at least on three occasions in the two months before inclusion.

We excluded children with a systolic or diastolic blood pressure above the 97 th centile for age, heart disease requiring treatment, a history of cardioarrhythmia, or diabetes mellitus. Patients receiving steroids, $\beta_{2}$ adrenoceptor agonists or antagonists or xanthine derivatives were also excluded.

Eight patients were treated by haemodialysis and three by peritoneal dialysis. Age ranged from 5-18 with a mean of 11.5 years. The mean plasma creatinine concentration before inclusion into the study was $914 \mathrm{mmol} / \mathrm{l}$. The mean pretreatment plasma potassium concentration was $5.6 \mathrm{mmol} / \mathrm{l}$ before the intravenous treatment and $5.9 \mathrm{mmol} / \mathrm{l}$ before the nebulised dose was administered.

At the start of either treatment patients had been off haemodialysis at least 24 hours or dialysis was suspended for 12 hours in those treated by peritoneal dialysis. Both dialysis groups were deprived of any potassium or sugar containing food for at least six hours before and during each treatment. Patients were randomised as to which treatment regimen to receive first, going on to receive the other at least one week later.

Salbutamol was given intravenously by infusion at a dose of $4 \mu \mathrm{g} / \mathrm{kg}$ in $10 \mathrm{ml}$ of water for injection over 20 minutes and the same dose was repeated at 120 minutes. Nebulised salbutamol was given over 10 minutes, at a dose of $2.5 \mathrm{mg}$ if they weighed less than $25 \mathrm{~kg}$, and 5 $\mathrm{mg}$ if they were above this weight, and then the same dose was repeated at 120 minutes.

Blood was taken from a heparinised, large, indwelling cannula before the start of either treatment and at $30,60,90,120,150,180$, 240 , and 300 minutes. These samples were analysed within 30 minutes for plasma potassium using an ion selective electrode (Parallel Analyser, American Monitor).

Children were monitored continuously on an electrocardiographic monitor and had their blood pressure and pulse measured every 30 minutes. Any adverse effects were noted when present.

Informed consent was obtained from the children and parents. The study protocol was approved by the local research ethics committee. 
Statistical analysis was by unpaired Student's $t$ test and a $\mathrm{p}<0.05$ value was accepted as significant. The results are expressed as mean (SE).

\section{Results}

The effect of intravenous and nebulised salbutamol on the mean plasma potassium concentrations are shown in figs 1 and 2 respectively.

When the group received the intravenous regimen, 30 minutes after the start of treatment there was a rapid and significant fall in plasma potassium concentration of $0.87(0.08)$ $\mathrm{mmol} / \mathrm{l}$. Just before the second dose at 120 minutes the potassium was still significantly reduced by $0.43(0.07) \mathrm{mmol} / \mathrm{l}$. Within 30 minutes after the second dose at 120 minutes there was a significant further reduction to $1 \cdot 16(0 \cdot 12) \mathrm{mmol} / \mathrm{l}$ below the initial pretreatment plasma potassium concentration. At 120 minutes after this second dose the potassium was still significantly reduced below the initial pretreatment concentration by $0.81(0.12)$ $\mathrm{mmol} / \mathrm{l}$.

The group on receiving the nebulised regimen had a significant reduction of 0.61 $(0 \cdot 12) \mathrm{mmol} / \mathrm{l}$ in their plasma potassium at 30 minutes after the start of treatment. Just before their second dose at 120 minutes the reduction had actually increased to $0.67(0.09) \mathrm{mmol} / \mathrm{l}$. After this second dose there was a further reduction, although significance was only reached after 60 minutes with a concentration of $1.14(0.12) \mathrm{mmol} / \mathrm{l}$ below the initial pretreatment measurement. At 120 minutes after the second dose the plasma potassium was still significantly reduced by $1 \cdot 14(0 \cdot 12) \mathrm{mmol} / \mathrm{l}$.

At the end point of the study at 300 minutes the level of reduction in plasma potassium in the nebulised group was significantly greater than in the group receiving salbutamol intravenously $(1.19$ compared with $0.7 \mathrm{mmol} / \mathrm{l})$. At no other time was a significant difference shown between the two methods of administration.

In the 10 children who received the intravenous treatment six experienced mild short lasting tremor alone, one mild vasomotor

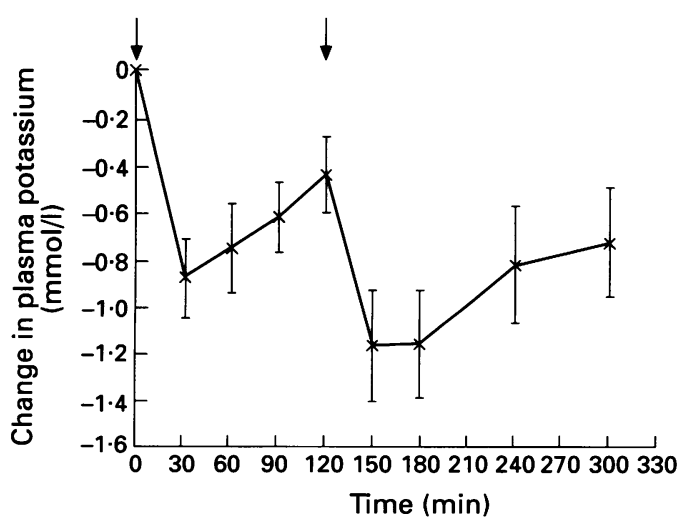

Figure 1 The change in plasma potassium (mmoll) with time after treatment with intravenous salbutamol; arrows indicate the point of each administration. Horizontal bars show the $95 \%$ confidence interval calculated from the SEM.

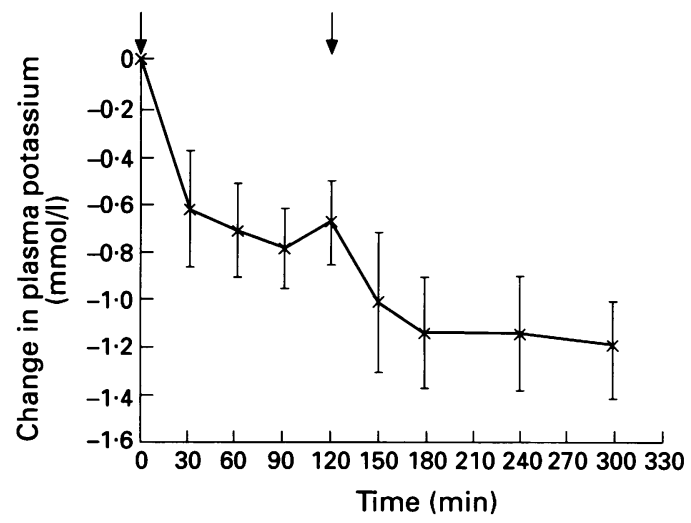

Figure 2 The change in plasma potassium (mmoll) with time after treatment with nebulised salbutamol; arrows indicate the point of each administration. Horizontal bars show the $95 \%$ confidence interval calculated from the SEM.

flushing alone, and three no adverse effects. In the 10 children who were treated with nebulised salbutamol four experienced tremor alone, two tremor with nausea, one mild vasomotor flushing alone, one had both tremor with vasomotor flushing, and two no adverse effects. In all patients there was a mild rise in heart rate but none above 140 beats per minute and none had a cardiac arrhythmia. No patient experienced a rise in systolic or diastolic blood pressure greater than $10 \mathrm{~mm} \mathrm{Hg}$ at any stage.

\section{Discussion}

In children with renal failure the definitive treatment of hyperkalaemia is dialysis, possibly supplemented with ion exchange resins. These treatments have, compared with others, the advantage of removing potassium from the body. Unfortunately they have the disadvantage of not always being readily available and, if they are, being relatively slow in their onset of action.

An ideal emergency treatment that is widely available, safe, easy to use, reliable, quick both to start and in its speed of action has therefore been sought. Various treatments have been used over time.

The efficacy of bicarbonate infusions, still used in some centres has been questioned. ${ }^{1}$ Dextrose and insulin either alone or together are standard in many units but have the hazard of hypoglycaemia.

$\beta_{2}$ Adrenoreceptor agonists, usually using salbutamol, have recently come into increasingly widespread use. They are believed to act by binding to $\beta_{2}$ adrenergic receptors, on muscle and liver cell membranes most importantly. 3'5' Cyclic AMP is produced from ATP via the resultant stimulation of adenylate cyclase. $3^{\prime} 5^{\prime}$ Cyclic AMP then acts on the sodium/potassium ATPase pump transferring potassium into the intracellular space. ${ }^{2}$ This lowers the risk of a cardiac arrhythmia developing when a child has hyperkalaemia because of the resultant reduction in the transmembrane gradient of potassium between the extracellular and intracellular space. It is interesting to note that although insulin with glucose also lowers plasma potassium by stimulating the sodium/ potassium ATPase pump, it is believed to act 
on a different receptor and has been shown to have a synergistic effect with salbutamol. ${ }^{3}$

The use of salbutamol is supported by evidence from studies involving adults that show that $\beta_{2}$ agonists lower plasma potassium in patients either with normal renal function ${ }^{4-6}$ or complete renal failure (acute or chronic). ${ }^{78}$ Murdoch et al significantly reduced the mean plasma potassium of 13 children who suffered either acute or chronic renal failure by treatment with intravenous infusions of salbutamol, $4 \mu \mathrm{g} / \mathrm{kg}$ over 20 minutes $(1.48$ and $1.64 \mathrm{mmol} / \mathrm{l}$ after 40 and 120 minutes respectively)..$^{9}$ There has been relatively little other assessment of salbutamol in this context in children.

Our study confirms the potassium lowering effect of salbutamol ( $4 \mu \mathrm{g} / \mathrm{kg}$ as a constant infusion over 20 minutes) when given intravenously to children with chronic renal failure. We have also shown that salbutamol is effective when nebulised using similar doses to those given for acute asthma attacks. This confirms the findings of Allon et al ${ }^{310}$ in adults and differs from Stemmer et al who proposed a 'uraemic inhibitor' which blocked the effect on potassium of salbutamol in chronic renal failure. ${ }^{11}$

Our results show that salbutamol given at these dosages by either route causes the plasma potassium concentration still to be significantly lower than the pretreatment level at 120 minutes. The potassium is also shown to fall significantly to even lower concentrations by a second dose of either regimen at 120 minutes. At the point where our study finished at 300 minutes after the first dose, the concentration of potassium was still significantly reduced. We have shown that the effect of lowering potassium by salbutamol by either route is repeatable and can be prolonged in patients with chronic renal failure. It would be useful to know how often this effect is repeatable and therefore how long it can last before saturation may occur, although five hours is time enough for almost all clinical situations.

While no significant difference was shown between the speed of onset in action of the two methods of administration, salbutamol given intravenously appeared to have a faster onset of effect than when nebulised. However most units would be able to set up a nebuliser faster than an infusion.

It would appear though that the fall in the concentration of potassium is more controlled when nebulised salbutamol is used. Other factors in favour of using the nebulised route are its wider availability, ease of setting up, avoidance of the need to locate and maintain intravenous infusions with all the associated risks, as well as the greater familiarity of staff with the dose and technique of giving salbutamol this way. This is in addition to the significantly greater reduction in plasma potassium at the end of the study seen in the nebulised group. Unfavourable factors include the possibility of a higher risk of mostly self limiting side effects that our study suggested happened when using the nebulised route together with the lack of certainty about the actual dose the child receives, particularly in the very young.

We can see no reason why children who have hyperkalaemia, with normal renal function or acute renal failure, should not respond to salbutamol in the same manner as above.

In conclusion salbutamol by infusion or nebuliser has a rapid, safe, and reliable effect in reducing plasma potassium in children with end stage chronic renal failure. This effect can be increased and prolonged by a repeat dose two hours later. There is a demonstrable difference in effect between the two methods of administration favouring the nebulised route. Salbutamol given by a nebuliser has several other advantages and we recommend this as the emergency first treatment of choice, supplemented by other treatments if necessary for all children with dangerous hyperkalaemia including those without end stage chronic renal failure. Patients who are on drugs that block salbutamol, for example atenelol, should not be treated this way and those suffering hypertension or cardiac disease need individual consideration.

We thank the following for their help with this study: Professo $S$ R Meadow, Dr $M$ Henderson, and the nursing staff of $S t$ James's University Hospital, Leeds.

1 Blumberg A, Wiedmann P, Shaw S, Gnadinger M. Effect of various therapeutic approaches on plasma potassium and major regulating factors in terminal renal failure. $\mathrm{Am} \mathrm{f}$ Med 1988; 85: 507-12.

2 Rosa RM, Silva P, Young JB, et al. Adrenergic modulation of extrarenal potassium disposal. N Engl $\mathcal{F}$ Med 1980; 302 431-4.

3 Allon M, Copkney C. Albuterol and insulin for the treatment of hyperkalaemia in haemodialysis patients. Kidney Int 1990; 38: 869-72.

4 Neville A, Palmer JBD, Gaddie J, May CS, Palmer KNV, Murchison LE. Metabolic effects of salbutamol: compariMurchison LE. Metabolic effects of salbutamol: compari-
son of aerosol and intravenous administration. BMf 1977 ; i: $413-4$.

5 Rolf Smith S, Ryder C, Kendall MJ, Holder R. Cardiovascular and biochemical responses to nebulised salbutamol in normal subjects. British fournal of Clinical Pharmacology 1984; 18: 641-4.

6 Hallbloom JRE, Deenstra M, Struyvenberg A. Hyperkalaemia induced by inhalation of fenoterol. Lancet 1985; i: 1125-7.

7 Montoliu J, Lens XM, Revert L. Potassium-lowering effect of albuterol for hyperkalaemia in renal failure. Arch Intern Med 1987; 147: 713-7.

8 Lens XM, Montoliu J, Cases A, Campistol JM, Revert L Treatment of hyperkalaemia in renal failure: salbutamo Treatment of hyperkalaemia in renal failure: salbutar

9 Murdoch IA, Dos Anjos R, Haycock GB. Treatment of hyperkalaemia with intravenous salbutamol. Arch Dis Child 1991; 66: 527-8.

10 Allon M, Dunlay R, Copkney C. Nebulised albuterol for acute hyperkalaemia in patients on haemodialysis. $A n n$ Intern Med 1989; 110: 426-9.

11 Stemmer CL, Perez GO, Oster JR. Impairment of $\beta_{2}$ adrenoreceptor-stimulated potassium disposal. $N$ Engl $f$ Med 1980; 302: 431-4. 